\title{
O CERRADO NA CARACTERIZAÇÃO DOS PERSONAGENS DE RICARDO GUILHERME DICKE
}

\author{
The role of the tropical savanna in Ricardo \\ Guilherme Dicke's characters
}

\author{
Tania Martuscelli*
}

\begin{abstract}
RESUMO
Com base na premissa de que a ecocrítica na literatura desenvolve uma análise da relação entre o humano e o ambiente, propõe-se a extensão da noção de literatura sertaneja, nordestina, para um conceito mais abrangente de "literatura do cerrado". A pesquisa de uma identidade das populações que habitam esse bioma maior ainda não foi dada a conhecer. É Darcy Ribeiro quem, em seu modelo de classificação rural (1978), delimita a cultura sertaneja entre as regiões do sertão nordestino, do cerrado do centro-oeste e do noroeste de Minas Gerais. Gilberto Freyre, com seu Manifesto Regionalista, argumenta a dissolução das fronteiras em nome de uma cultura brasileira, nacional. Propomos desenvolver uma análise literária ecocrítica de modo a comparar os ecossistemas do cerrado e do sertão, sugerindo que há certo viés coincidente na identidade cultural literária desses dois espaços geográficos. O foco deste trabalho será nos romances do matogrossense Ricardo Guilherme Dicke, Deus de Caim e Os Semelhantes.
\end{abstract}

Palavras-chave: Ecocrítica; literatura sertaneja; Ricardo Guilherme Dicke.

* University of Colorado at Boulder. 


\begin{abstract}
Based on the assumption that literary ecocriticism analyses the relationship between humans and the environment, we propose to extend the notion of Norheastern literature of "sertão", or of the hinterland, to a broader concept of "literature of cerrado" or the ecoregion of tropical savanna in Brazil. The search for a common identity among the population confined within this broader ecoregion has yet to be made. Based on Darcy Ribeiro's model of classification of rural population (1978), and in Gilberto Freyre's Regionalist Manifesto (1926), we propose to develop a literary analysis that parallels both ecoregions of tropical savanna and the hinterland. Ribeiro marks boundaries of the sertanejo culture within the Northeastern backlands, the Weastern tropical savanna, and the Northweastern region of Minas Gerais, while Freyre argues for a blur of the frontiers in the name of a national identity. We propose that there are some coinciding aspects in the literature of the two areas of hinterland and tropical savanna. The focus of this study will be on Ricardo Guilherme Dicke's novels Deus de Caim and Os Semelhantes. Dicke is an author from the state of Mato Grosso.
\end{abstract}

Keywords: Ecocriticism; sertão literature; Ricardo Guilherme Dicke.

Se se pensar na ecocrítica enquanto análise da relação do ser humano e o meio em que vive refletida na literatura, pode-se propor uma extensão do que se reconhece como "literatura do sertão", enfocada no nordeste brasileiro, para uma delimitação mais abrangente, de modo que se inclua ao bioma da caatinga também o bioma do cerrado. Tal proposição teria por base a classificação de modelo de povoamento rural de Darcy Ribeiro, que delimita a "cultura sertaneja” pelo que constitui o nordeste seco, o cerrado do centro-oeste brasileiro e o noroeste de Minas Gerais, por conta do que se transformou numa cultura da criação de gado. Desse modo, ao se analisarem duas obras do matogrossense Ricardo Guilherme Dicke, Deus de Caim e Os Semelhantes, pode-se pensar tanto numa "literatura do sertão" com certos caracteres distintos daqueles bem conhecidos da região seca do nordeste, como numa "litetatura do cerrado", esta menos familiar para os leitores. Por outro lado, sob o ponto de vista regional, o cerrado neste caso, pode ultrapassar a fronteira da bem conhecida literatura sertaneja, ou ainda, borrar os limites de cada região. Com base ns argumentos apresentados no inaugural Manifesto Regionalista de Gilberto Freyre, de 1926, pode-se anotar que a dicotomia da modernidade e da tradição são recorrentes tanto no que se refere à relação centro e periferia entre sertão, cerrado e grandes cidades. 
A primeira, a modernidade, era - e diga-se mesmo que de modo atrevido, é ainda no Brasil - culturalmente relacionada à ideia de americanização ou europeização do país em detrimento de sua característica nativa. Freyre sublinhou o crescente "horror à árvore" em nome de "avenidas americanamente largas" (1996, s.n.p) em seu texto, reclamando que o país era composto de regiões sociológicas, isto é, "[r]egiões naturais a que se sobrepuseram regiões sociais" (1996, s.n.p). Freyre defendeu ainda em seu manifesto regionalista que a cultura brasileira deveria ser percebida sob o prisma complementar homem e paisagem. Neste contexto, tem cabimento redimensionar a obra de Dicke ao parâmetro regional, ainda que não se trate de regionalismo literário (ou de neo-realismo), mas de analisar o texto do matogrossense sob o prisma da ecocrítica, considerando o cerrado como paisagem.

Guilherme Dicke (1936-2008) é contemporâneo de reconhecidos e alguns canonizados autores do sertão. Tendo sido referido por Guimarães Rosa como romancista "capaz de abalar a nossa ficção", ${ }^{1}$ por Hilda Hilst como um dos "gigantes" da literatura nacional, ${ }^{2}$ por Marçal Aquino como "ferozmente original" ${ }^{3}$ e por Glauber Rocha como "o maior escritor brasileiro", ${ }^{4} \mathrm{o}$ autor surge no panorama literário como detentor de um conhecimento da cultura e da figura do sertanejo matogrossense que, como aquelas do sertanejo nordestino, são postas à margem.

No caso dos personagens-tipos que aparecem na obra de Dicke e sua relação intrínseca com o ambiente que os cerca, os garimpeiros, os tropeiros, as prostitutas, os empreendedores, bem como os oportunistas, os ladrões, etc., que são desconhecidos, se não mesmo ignorados - porque à margem político-social brasileira, no plano da realidade, na obra de Dicke são personagens que delineiam o que está-se propondo chamar de literatura do cerrado. Sua obra cumpre, neste sentido, o mesmo papel da literatura num âmbito mais geral (de linhagem ocidental, pode-se dizer) que se propõe a dar voz e dimensão às figuras deslocadas à margem do poder.

Se se entender o ecológico nos dois romances, Deus de Caim e $O S$ Semelhantes, como oikeion (ou eco), isto é, o espaço privado, ou "recluso", a tudo que não é politikon, isto é, ao que seria próprio da esfera pública, segundo o estudo de Jean-François Lyotard, pode-se já de antemão propor

1 Guilherme Dicke (1936-2008) é contemporâneo de reconhecidos e alguns canonizados autores do sertão. Tendo sido referido por Guimarães Rosa como romancista "capaz de abalar a nossa ficção",

2 A afirmação de Hilst é citada no artigo de Rodrigo Vargas, "Ricardo Guilherme Dicke ganha edição póstuma de quatro obras - Lançamentos apresentam originais deixados para a família”, na Folha de São Paulo.

3 Op.cit. Ibidem.

4 Glauber Rocha é referido no posfácio à edição de 2010 de Deus de Caim, de Ricardo Guilherme Dicke (p. 397-398). 
uma análise do caráter dos personagens por via de seus pensamentos e consequentemente suas ações como modo de contrastar o público e o privado na sociedade matogrossense. Note-se que no que se refere ao recluso, ao escondido, bem como ao que está à margem, torna-se conhecido por via exclusiva da experiência com o texto literário. O oikeion, como observa ainda Lyotard, não se refere unicamente ao reino vegetal, mas ao que está inscrito na origem de todo aparato mental, psíquico e espiritual. o autor retoma Freud e recontextualiza o conceito de "economia psíquica", ou "economia libidinal" - donde oikonomikos ou oikonomikon, torna complexa a definição fechada do "eco", uma vez que "'economic' means the public sphere, (...) the oikos itself has slipped away elsewhere" (2000, p. 136). Se em Freud a economia (psíquica, libidinal) pressupõe que algo escape ou resista ao que é da ordem pública, que seria o papel do inconsciente, na opinião de Lyotard, a contradição, a tensão, a repressão, o deferimento, o deslocamento e a distorção, isto é, a modificação de força, massa e volume é a representação física (portanto pública) daquilo que considera ecologia psíquica.

Tais aparatos (mental, psíquico e espiritual) podem ser sublinhados na composição dos romances de Dicke. Os personagens do cerrado, tanto os representates do interior quanto os da cidade, tanto os mais humildes quanto os mais adinheirados, enfileiram-se à tradição ocidental de herança judaico-cristã, não se diferenciando, desse modo, de um universo cultural mais abrangente, brasileiro. Em Deus de Caim, a índole dos personagens é explicada como sendo

todos humanos, filhos de Deus, segundo Abel ou segundo Caim. O deus de Abel era manso e bom, e amava o sacrifício dos Abéis do mundo. Já o deus de Caim era ruim e pervertido como os Cains que protegia e a eles recusava a chama loura das aras dos holocaustos. ${ }^{5}$

Tais personagens se inserem, portanto, num universo em que bem e mal, ou a moral propriamente dita, passam por um crivo maior, de índole própria do que é de ordem mística e mítica. Este universo, em certo sentido, não pode ser controlado por seus habitantes, apresentados como meros herdeiros genéticos de um deus que é pai de Caim ou de Abel.

Juntem-se às definições e redefinições do oikos a noção de ecossistema, que Greg Garrard, ao demonstrar a relação entre o pastoril da literatura clássica e neo-clássica e a tradição judaico-cristã, afirma que o ambiente natural pode assumir três orientações: uma de sentido nostálgico, outra de um lugar idílico e a terceira utópica. A primeira representaria o passado, a segunda, o presente e a última, o futuro. As três orientações de Garrard 
podem ser reivindicadas aqui para analisar não somente o interior do Mato Grosso, espaço físico da natureza do cerrado, como também a capital urbana. A descrição de Cuiabá, por exemplo, pode ser lida como um espaço "pastoril" - ou rural - nostálgico, uma vez que o olhar do personagem a denuncia, no presente, como lugar que havia conhecido distinto, ainda próximo da orientação idílica:

Havia um grande tamarindeiro - com que ternura lembrava daquela portentosa árvore! - hoje ali não há mais nada, só edifícios nus, repartições monótonas, tudo cimento, funcionários aborrecidos que levam e trazem processos, transitando nos corredores como sombras. (...) Oh aquele tamarindeiro, tão grande que podiam caber no seu corpo de galhos e folhas quarenta ônibus engavetados ${ }^{6}$

o passado nostálgico é representado pelo tamarindeiro que já não existe, ao passo que anuncia um presente sem alma. o que antes era sombra das árvores, passa a ser funcionários-quase-zumbis de repartição pública. O que eram grandes galhos cobertos de folhas, hoje seriam "quarenta ônibus engavetados". Não há, consequentemente, uma visão utópica do futuro, mas destruidora do espaço idílico. Em certo sentido Gilberto Freyre já havia apontado em seu Manifesto Regionalista para um "modernismo ou ocidentalismo que vê em tudo o que é antigo ou oriental um arcaísmo a ser abandonado" (1996, s.n.p), cujo horror caricato às árvores e excesso de uso de concreto acabaram por levar o autor a caracterizar o Brasil nos anos de 1920 como um "blagueur" do que lhe é estrangeiro: "só sabe derrubar (...) palmeiras antigas, gameleiras velhas, jardins ou hortos coloniais, contanto que (...) se assemelhem às mais modernas cidades norte-americanas ou francesas" (1996, s.n.p). Pode-se aventar que a paisagem de destruição na obra de Dicke vai ser influente na atitude dos personagens da cidade, o que uma vez mais corrobora com a proposta freyriana de contextualizar homem e paisagem, o que mais adiante será analisado em detalhes.

No romance Deus de Caim, dois irmãos, Jônatas e Lázaro, habitantes da região de Pasmoso, amam a mesma mulher, Minira. Acreditando ter matado Lázaro, Jônatas tenta sequestrar a moça, namorada de seu irmão, mas leva um tiro durante o ataque e vê-se obrigado a fugir. $O$ antagonista do romance pede abrigo na casa de um tio, empreendedor rico em Cuiabá, que lhe oferece um teto e cuidados médicos. Jônatas, assim que se recupera, logra raptar Minira e levá-la para o quarto da casa onde está hospedado. Prende-a e a violenta, imaginando poder convencê-la de seu amor, ainda que à força. Lázaro, que afinal não havia morrido, vai em direção à cidade 
em busca da namorada e, quando chega à mansão do tio, testemunha um incêndio de proporções bíblicas, que destroi por completo a casa, matando quase todos que ali estavam e quase morrendo ele próprio sufocado pela fumaça enquanto salvava a namorada, já grávida do irmão.

A índole de Caim ou de Abel, ou o parâmetro religioso, é mote para a construção do caráter não somente dos personagens Lázaro e Jônatas, mas também de outros, como o dos personagens primos do heroi, todos filhos do tio rico da cidade. Carlos e Sílvia, por exemplo, eram irmãos, mas mantinham uma relação incestuosa. Pode-se pensar que o ambiente que cerca os personagens tanto na cidade como na zona rural colabora - ou corrobora - com suas ações, já que em harmonia com o referido oikos de cada lugar. A casa incendiada em Cuiabá havia sido palco de festas tão excêntricas quanto entediantes, além de ter sido o lugar do encontro amoroso entre os irmãos e o cativeiro de Minira. $O$ ambiente rural cumpre a função de compor um cenário de abandono, lugar marginal do país em que a violência é retratada em estado bruto.

Num oikos tão embrutecido quanto embrutecedor, podem-se verificar semelhanças com o sertão nordestino, mais familiar para os leitores, por ser assolado pelo incontornável calor do sol:

Em torno, pesava o grande silêncio das cidades esquecidas, à beira do tempo. (...) velhos muros e gastas paredes das casas, com suas telhas vermelhas, roídas pela cárie ancestral, doença do tempo corroendo o próprio ar. (...) As coisas pareciam não ter sombra. Era a hora em que o sol, no pino do céu, é o centro do círculo dos horizontes. Nos ouvidos, o marejar indeciso do sangue, do silêncio dos lugares perdidos. ${ }^{7}$

Por outro lado, é possível diferenciá-lo do nordeste seco, porque é um lugar onde também se sofre com a chuva: "A tormenta vem aí, forte como o diabo solto. Como um grande ventre cheio de intestinos que roncam por arte de todos os empanturrares, a extensão do céu ruge e muge à boca-quiúsa de roncos eletrizados." ${ }^{8} \mathrm{O}$ espaço natural obriga que seus moradores adquiram certa resistência física, moral e religiosa para que não sucumbam ao ambiente.

Em Deus de Caim, por exemplo, Jônatas, que julgava ter matado o irmão explica-se:

Digam o que digam. Que sou ruim mesmo. (...) Sei o que é o sangue de nossa gente. Meu pai teve várias mortes no lombo. Até minha mãe, que rezava o rosário, matou gente (...) O tio Jairo, irmão da 
mãe, também teve seus casos. Morreu matado, mas matou em vida muita gente (...) tinha uma coleção de orelhas em casa, igual que os jagunços do Nordeste. ${ }^{9}$

A "literatura do cerrado" pode ser lida como lugar que compreende de maneira exemplar a ecologia psíquica lyotardiana sob o ponto de partida da ecocrítica. Em Deus de Caim, na cena em que o casal de irmãos incestuoso é descoberto pela tia, a casa (oikos) em que vivem acolhe tanto as atitudes dos irmãos, quanto a censura da tia que condena-os em pensamento pelo pecado, o que é marca da herança judaico-cristã. De igual modo, a referida dinâmica de ecologia, economia e política, que deve ser entendida como o espaço privado, o espaço público e a esfera do público que esconde a esfera do privado, abarca as atitudes e pensamentos dos personagens do romance. No caso dos personagens principais, tal ecologia psíquica adquire foros de mito: Lázaro é de boa índole e Jônatas é de má índole. Minira termina a narrativa casada com um (o protagonista) e grávida do outro (o antagonista, seu violador) que, morto, vive dentro dela:

Minira, a vagina em transe, secretando humores quando se lembrava de Jônatas. Jônatas, o membro assombrando-se em vagos ímpetos varados na muda recordação dos mortos, ao correr por ele a recordação trepidante do corpo de Minira. Lázaro, os lábios sangrando de mordidas, o ruído ouvia dos dentes - triturando os próprios pensamentos. ${ }^{10}$

Há uma constante dinâmica entre passado, presente e futuro, para voltar a referir Garrard, e ainda uma atmosfera que reúne mítica e misticamente, poder-se-ia aventar, a ideia de nascimento e morte (Minira dá vida ao filho de um pai morto), de prazer e de pecado (Minira sente desejo por seu violador), que são resultados da contradição, tensão, repressão, deferimento, deslocamento e distorção, ou da "ecologia psíquica". Lázaro, assumindo um papel quase mítico, está condenado eternamente, apesar de não ter cometido pecado nenhum. Resignado, ao mesmo tempo que revoltado, o personagem se indaga: "O filho viria, sim, mas isso não seria capital. Como, entretanto, pronunciar o nome do outro (...) separado deles, por séculos e séculos sem medida, geológicos, numa sucessão de infinitos?" 11

Lyotard assinala ainda o paradoxo em relação à herança judaico-cristã e o tempo. O filósofo sublinha que não se nasce pronto para fazer pronunciamentos ou para controlar o ambiente cercano, mas nasce-se dentro de uma cultura pré-estabelecida, num contexto de muitas narrativas e 
significados dos quais não se participa, mas que acaba por ser herdado. É o caso do deus de Caim ou de Abel na obra de Ricardo Guilherme Dicke, em cujo cerrado, não completamente distinto de um sertão nordestino, é descrito como o "sertão largado de Deus", ${ }^{12}$ em que os personagens "moravam naquele oco do mundo" ${ }^{13}$ e os leitores são advertidos que "o pesado sertão é uma verdade, sertão duro, de punhal e cruz, onde só os pais de Deus e os filhos do Diabo entram, em que a porta do mundo fica para trás." ${ }^{14}$

É exemplar o caso do velho lendário Antônio Gurgéis, em Os Semelhantes, que, depois de ter seu filho de dois anos raptado talvez por ciganos, passa o resto da vida a procurá-lo. Paradoxalmente, ou corroborando com uma imagética de tempo mítico ("O velho limpava as lágrimas que nunca se secavam e, quanto mais as enxugava, mais vinham"), carrega consigo os ossos desse filho, que é um "monte mal cheiroso [em que] avultava a caveira ainda com cartilagens a olhar com os buracos sem olhos". ${ }^{15}$ Tal ossada era de um boi e não do filho, que jamais encontraria. O velho acreditava piamente que o menino já crescido estava vivo em Cuiabá, ao mesmo tempo que tinha consigo seus restos mortais e ainda dizia a todos que era a criança que morava com ciganos. Ao ser questionado pela incongruência de ter um filho tanto vivo como morto, ainda criança, mas também adulto, em três formas distintas - em caveira, na cidade, entre os ciganos -, o velho responde de modo a confirmar uma herança judaico-cristã ainda que descontextualizada e recontextualizada, mesmo que paradoxal em relação ao tempo: "a Santíssima Trindade não é assim também?"16

No romance, Os Semelhantes, Abadia é um mineiro que mata seu companheiro de garimpo por causa de uma pepita de diamante. Em seguida, rouba o burro de estimação de seu vizinho Rosendo para buscar Umbelina, uma prostituta local, e casar-se com ela. No caminho, dá carona a um cego e a Ramonita, moça que está à procura de seu namorado, o dono do burro que, por sua vez, havia saído em desespero em busca do ladrão de seu animal favorito. Abadia, bêbado e impaciente, acaba por matar o burro a chicotadas quando este empaca na lama. Já alucinado - ou alucinando-, mata também o cego e só não viola a moça porque desmaia em coma alcoolico, dando chance a Ramonita de lhe roubar o diamante. Por vinte anos Abadia vive como um alcóolatra e mendigo em Aguassu, remordido pelo assassinato do companheiro de garimpo e pela perda de sua chance de se casar com Umbelina, que havia se mudado a Cuiabá. Depois desses vinte anos, maltratado

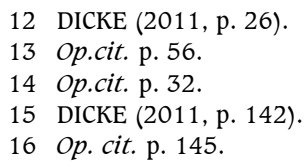

Revista Letras, Curitiba, n. 92 p. 82-95, JUL/DEZ. 2015. ISSN 2236-0999 (VERSÃo ELETRÔNICA) 
e já sem saúde, decide ir à cidade à procura de sua velha namorada. Lá, Umbelina é empregada e amiga de Ramonita, que havia se tornado, graças à venda do diamante, em dona de bordel, jamais tendo encontrado Rosendo na época do sumiço de seu burro. No desfecho da narrativa, Ramonita e Rosendo se reencontram, mas o moço não a perdoa pelo crime de roubo da pepita. Decepcionada, a cafetina se envenena e, ainda que seja encontrada em seu quarto com vida por Umbelina, a amiga deixa-a morrer para poder apossar-se de sua fortuna. Abadia aparece durante o velório e afirma que a casa e o negócio do bordel são dele, dono do diamante roubado. Rosendo entretanto recorda que o ex-garimpeiro havia sido o primeiro ladrão da pedra de seu amigo, prometendo denunciá-lo à polícia. $O$ até então mendigo, velho, doente, falece antes mesmo da chegada da polícia, cansado da viagem e esgotado com as emoções do dia.

Ao apontar para a tendência que a literatura ecocrítica tem de descentralizar o objeto narrado em nome de uma recentralização no pensamento ecológico, isto é, redimensionar a literatura a um compromisso ecológico ou ambiental, Dominic Head defende que os autores buscam dar voz tanto ao Outro não-humano, como ao marginalizado. ${ }^{17}$ Nesses casos, a presença da natureza no texto enquanto modo de perceber organicamente a narrativa literária, vai além de questões deterministas, relacionadas, por exemplo, com as correntes naturalistas, ou com o próprio regionalismo. Se por um lado é possível argumentar uma análise ecocrítica de um (qualquer) texto literário, e identificar mais facilmente o aspecto ambiental nos romances do Naturalismo e Regionalismo, com "literatura ecocrítica" quer-se propor uma revisão dos parâmetros literários e ênfase no que normalmente é pano de fundo da narrativa: o ambiente, o oikos, o ecológico. Evidentemente não é esta a postura de Ricardo Guilherme Dicke enquanto ficcionista. Contudo, ao abordar elementos referentes à uma literatura do cerrado, ainda que imediatamente se possa pensar num certo regionalismo, não se propõe limitar a ler os textos enquanto simples retrato, ou relato de uma região, o que poderia acarretar no estereótipo. No presente caso, a proposta de uma análise ecocrítica é a de dar voz a um Mato Grosso marginalizado no plano da realidade e de certo modo esquecido no campo literário. Outra opção seria lançar-se aos estudos culturais para analisar o texto, como fizeram, por exemplo, Precioso e Falcão (2014), o que significaria, contudo, abrir mão da postura política, ambientalista não do autor, mas do crítico.

Apesar de ser uma região singular em muitos sentidos, o cerrado traz à luz questões que se coadunam com o que se conhece ou se reconhece 
no sertão brasileiro, enquanto literatura sertaneja, cuja expressão nordestina é mundialmente lida além de ter sido referência para outras literaturas de expressão portuguesa (e, diga-se, herdeira, a brasileira, de um regionalismo norte-americano). Por outro lado, essa "literatura de cerrado" também traz à luz questões que se coadunam com a literatura brasileira num âmbito mais geral. Aliás, há diversos contextos em que um oikos marginalizado se torna central na literatura contemporânea, tanto rural como urbana, tanto no cerrado como fora dele. Merece retomar o manifesto freyriano uma vez mais, para apontar que a singularidade, bem como a comunhão de características culturais das regióes brasileiras não as separam, mas formam a identidade nacional do país. $O$ autor esclarece que o regionalismo, como ele o imagina,

é tão contrário a qualquer espécie de separatismo que, mais unionista que o atual e precário unionismo brasileiro, visa a superação do estadualismo, lamentavelmente desenvolvido aqui pela República - este sim, separatista - para substituí-lo por novo e flexível sistema em que as regiões, mais importantes que os Estados, se completem e se integrem ativa e criadoramente numa verdadeira organização nacional. ${ }^{18}$

Quer-se propor ainda que em Dicke a percepção da voz do não-humano, ou mais especificamente, da natureza do cerrado aparece por via orgânica no texto, de modo que o ambiente se estenda ao campo da complexidade dos personagens. Aventa-se, inclusive, à linhagem simbolista, quase que ao modo das Correpondências poético-pictóricas de Baudelaire, quando o autor matogrossense insiste no uso de cores para representar o bioma local que, de certo modo, remete o leitor a uma "psique" própria do ambiente narrado. São exemplos que denotam uma violência não-explícita, ou, para retomar Lyotard, uma violência que é da ordem do privado, compondo assim um aparato psíquico, mental e espiritual os seguintes trechos: "Um agouro daquela lua, já no outro lado do céu, roxosa, em sangues misturada, entre panos de nuvens"; ${ }^{19}$ ou: "no céu, via-se uma espécie de coágulo alaranjado e, sob a ponte, uma rumorosa pasta negra que nem se movia mais"; ${ }^{20} \mathrm{e}$ ainda: "via a lâmina amarelo-roxa da madrugada que já envolvia os morros e as matas." ${ }^{21}$ A escolha lexical de "sangues", "coágulo", "pasta negra", bem como "lâmina" apontam para a atmosfera de violência que se sente em forma de "agouro", ou de inevitabilidade, uma vez que "envolve" (a lâmina, isto é, o céu da madrugada) todo o lugar.

18 FREYRE (1996, s.n.p)

19 DICKE (2011, p. 26).

20 op. cit. p. 98.

21 op. cit. p. 53

Revista Letras, Curitiba, n. 92 p. 82-95, JUL/DEZ. 2015.

ISSN 2236-0999 (VERSĀo ELETRÔNICA) 
No contexto simbólico da cor, são de notar certas correspondências pouco óbvias, como lua roxosa, ou "Sol roxo", ou ainda um céu que é "sujo azul." ${ }^{22}$ Nota-se também o deslocamento de cor, textura e som, de modo a provocar a sinestesia visual, sensorial e auditiva, aumentando portanto o simbolismo da natureza em interação com o que é da ordem do humano no seguinte trecho:

Uma baba cor de pérola adormenta o céu daquele lado. E depois o roxo que viceja sujando o azul. Os morros se perdem na cintilação solar e todo o horizonte forma uma garoa espessa e barrosa que parece chapinhar circularmente rumo ao ponto que é o centro dum compasso sem fim. Os pássaros aqui nem voam. O calor derrete a espera do mato com seu silêncio pesado. Uma ideia de solidão pegando fogo toma a forma do ar e a luz tem a cor de todas as fagulhas. O céu é um vidro fosco, redoma cheia de fumaça e nuvens itinerantes com reflexos verdes, garrafa trincada por todos os lados contendo casas. $O$ sol muge. ${ }^{23}$

"Baba" aparece como referente para a cor do céu, "barro" é referente para a textura da garoa, o "mato", como se falasse, faz silêncio, o ar é fogo e o fogo é solidão, o céu é uma garrafa de vidro e o sol muge, como o gado.

É ainda com a imagem da violência em estado bruto que o autor escolhe iniciar as duas narrativas. Em Os Semelhantes, a interação do homem com a natureza tanto encoraja o crime como no trecho seguinte: "Atrás dele, céu aberto, vermelho de ferros rubros, se espraiava em volta em sangue manado, o sol como uma ferida aberta", ${ }^{24}$ quanto ajuda a esconder 0 assassinato. Quando Abadia leva seu companheiro morto para o rio, corta-o com um punhal provocando "um corte profundo, desde o peito à barriga." 25 Em seguida, joga o corpo ferido no rio para ser comido pelas piranhas, marcando seu conhecimento profundo da natureza para encobrir o crime e fazer desaparecer um amigo: "ouvia o barulho das piranhas. [Era] [c]omo cupins roendo madeira ou fogo quando caminha nos roçados." 26

o personagem Abadia, por vinte anos viveu atormentado, ou mais especificamente, assombrado pela traição ao garimpeiro. Seu modo de remoer o assassinato passa pela forma em que percebe a natureza a sua volta. A lua e o canto da mãe-da-lua, ave local, perpassa toda a narrativa. Ao cantar "[f]ui eu, fui eu, fui eu... Amanhã-eu-vou!", ${ }^{27}$ a mãe-da-lua provoca o medo no personagem, reflexo de seu sentimento de culpa, ainda que acreditasse 
ter feito o que era suposto, como explica o narrador: "ele matara um... Sempre tivera vontade, desde toda sua vida. E vida é para isso, para matar ou morrer." ${ }^{28}$ A possibilidade de eliminar o pássaro e nunca mais ouvir seu canto não resultaria no fim de seu assombro, porque a constante presença noturna da lua cumpria o mesmo papel da ave agourenta.

o poder da natureza na obra de Dicke, desse modo, impossibilita o homem de reagir contra os males que o atormentam. Pode-se argumentar que, nesse caso, o espaço natural adquire mais poder que o humano. A cultura do homem não é capaz de dominar completamente a natureza. $\mathrm{O}$ que vem do céu, além do calor do sol, da chuva e da atmosfera de assombro da lua, tem um significado intemporal, bem como espiritual ou moral e psíquico, que domina o que está no plano da terra. Tudo o que é terreno é descrito num mesmo plano - humano e natural - numa irmandade entre os que estão sob o jugo do céu.

As referências que aproximam humano e natureza no plano terreno e vice-versa são recorrentes, como no trecho

Era meio-dia. Fazia um grande silêncio. Vai chover. No céu se preparava o trabalho das águas. Quando assim decorre uma hora de véspera das tormentas a premonição invade os seres. Parece que vai haver coisas milagrosas, mas é apenas uma chuva que virá. Há um silêncio agonioso que antecede (...) Sem saber, os homens rezam aos poderes da natureza, como nos ritos antes do Tempo, impressionados por esse silêncio que sentem e não sabem. Nos campos, nos terreiros, nas roças, os bichos se enervam. Os homens se abrigam. Os insetos se recolhem. (...) As espessas mangueiras tremem..$^{29}$

Perante o fenômeno da chuva, que vem do céu intocável e jamais dominado, humano e natural são postos no mesmo nível no plano terrestre: os homens e insetos se abrigam, a plantação e os animais ficam nervosos, o pé de manga centenário treme.

Ainda no que se refere à ecocrítica, pode-se retomar outra questão, de ordem ética, de modo que o eco, ou oikos, o particular, o "lar", é lido como lugar que precisa de um espírito próprio, de um ethos, na visão, por exemplo, de William Howarth. O papel do ecocrítico, neste caso, é mostrar os méritos e desméritos dos efeitos da cultura sobre a natureza. Há, desse modo, uma questão ética, bem como uma ação política a ser apontada. Em Dicke, podem-se encontrar os efeitos da cultura sobre a natureza, com exceção do já referido poder do céu, seja ele de ordem natural ou sobrenatural. 
Neste caso, há um efeito da natureza sobre a cultura humana, que é uma espécie de vingança. A questão ética, combinada com a descentralização ou recentralização do objeto no pensamento ecológico, comprovam tal dominação. Especificamente nas duas obras de Dicke, percebe-se que a imagem de Deus, tanto quanto a do sol, da lua, da chuva e a do tamarindeiro destruído na cidade afetam $o$ ambiente terrestre.

Em Deus de Caim, Lázaro é velado pelo irmão que pensa tê-lo matado. Neste momento Jônatas, o antagonista, toma consciência da morte no lugar em que vive:

Sabia o que era a morte. Viviam dentro dela, respirando vida, mas tudo era estar-se para morrer, nada mais. Tinha de ser. E quem o soubera? Pé da serra do Juradeus, por perto de Cuiabá. Nem sertão, nem arrabalde. Mais ou menos. (...)Tão manso. Dava pra imaginar. Imaginas no quê? Qualquer coisa, ora bosta, mandar o irmão pros quintos, por exemplo. ${ }^{30}$

No universo sertanejo de Dicke, na dinâmica entre terra e céu, pesa sempre para o lado do mais fraco: o humano. O personagem do cerrado só é capaz de perceber seu domínio em relação à morte, isto é, quando tira a vida de outro. É preponderante o ato de matar, que dá a ilusória sensação de poder sobre a natureza, portanto a capacidade de modificar força, massa e volume. Tal é reflexo de uma ação política do autor matogrossense, que já havia afirmado em outra ocasião que a vida do sertanejo no cerrado era "para matar ou morrer". ${ }^{31}$ Dicke presenteia o leitor, desse modo, com a ecologia psiquica de seus personagens matogrossenses, demonstrando que, tal qual o personagem nordestino sertanejo, humano e natureza relacionam-se de modo intrinseco.

\section{REFERÊNCIAS}

DICKE, Ricardo Guilherme. Deus de Caim. 3. ed. Taubaté: LetraSelvagem, 2010. . Os Semelhantes. Cuiabá: Carlini \& Caniato Editorial, 2011.

FREYRE, Gilberto. Manifesto Regionalista. 7. ed. Recife: FUNDAJ, Ed. Massangana, 1996. p. 47-75. Disponível em: <http://www.ufrgs.br/cdrom/freyre/freyre.pdf>. Acesso em: 21 nov. 2015.

GARRARD, Greg. Ecocriticism. Londres; Nova Iorque: Routledge, 2012.

HEAD, Dominic. Ecocriticism and the Novel. In: COUPE, Laurence. (Org.). The Green Studies Reader: from Romanticism to Ecocriticism. Londres; Nova Iorque: Routledge, 2000. p. 235-241.

30 op.cit. idem.

31 DICKE (2011, p. 31).

Revista Letras, Curitiba, n. 92 p. 82-95, JUL/DEZ. 2015.

ISSN 2236-0999 (VERSÃo ELETRÔNICA) 
HOWARTH, William. Ecocriticism in Context. In: COUPE, Laurence. (Org.). The Green Studies Reader: from Romanticism to Ecocriticism. Londres; Nova Iorque: Routledge, 2000. p.163-166.

LYOTARD, Jean-François. Ecology as Discourse of the Secluded. In: COUPE, Laurence (Org.). The Green Studies Reader: from Romanticism to Ecocriticism. Londres; Nova Iorque: Routledge, 2000. p.135-138.

PRECIOSO, Adriana Lins; Iouchabel S. F. Falcão. Ricardo Guilherme Dicke e o Processo da Transculturação na Literatura. Estudos de Literatura Brasileira Contemporânea, n. 44, p.125143, jul./dez. 2014. Disponível em: <http://www.scielo.br/pdf/elbc/n44/a07n44.pdf>. Acesso em 24 nov. 2015.

RIBEIRO, Darcy. Os Brasileiros. 3. ed. Petrópolis: Editora Vozes, 1978.

VARGAS, Rodrigo. Ricardo Guilherme Dicke ganha edição póstuma de quatro obras - Lançamentos apresentam originais deixados para a família. Folha de São Paulo, 23 jul. 2011. Disponível em: < http://www1.folha.uol.com.br/fsp/ilustrad/fq2307201125.htm>. Acesso em: 26 mai. 2015.

Submetido em: 02/11/2015

Aceito em: 13/12/2015 